\title{
МЕТОДИКА
}

ВУ Нгок Винь,

канд. пед. наук, доцент Ханойского госуарственного университета (г. Ханой, Вьетнам)

Электронная почта: vinhiem2006@yahoo.com

ФАМ Куанг Лан,

аспирант Ханойского института иностранных языков при Ханойском государственном университете (г. Ханой, Вьетнам)

Электронная почта: lanpquang@gmail.com

\section{Универсальная модель разработки системы упражнений для обучения устному последовательному переводу вьетнамских студентов-филологов}

В статье рассматривается универсальная модель разработки системы упражнений для обучения устному последовательному переводу (УПП) вьетнамских студентов-филологов. В разработанную универсальную модель входят три блока упражнений: подготовительных, операционно-переводческих и собственно-переводческих. Каждый блок, в свою очередь, включает типы упражнений, призванных выработать соответствующие навыки, умения и операции УПП. Созданная на основе общепризнанных дидактических, общеметодических и частных принципов, учитывающих специфику обучения УПП, система упражнений моделирует типичные ситуации переводческой деятельности в соответствии с каждым из её этапов.

В настоящее время в целях удовлетворения возрастающей потребности общества как в специалистах, хорошо владеющих русским языком, так и переводчиках, способных устно переводить русскоязычную речь на вьетнамский язык, почти все факультеты русского языка и русской культуры языковых вузов Вьетнама расширяют масштаб подготовки студентовфилологов с переводческой ориентацией и повышают качество обучения данного контингента учащихся. Подготовка студентов-филологов к переводческой деятельности должна обеспечить снабжение их знаниями, умениями и навыками перевода, создающимися на основе использования специально подобранных учебных материалов с применением целесообразной методики обучения. Ключевым вопросом методики обучения перевода является система упражнений, поскольку упражнения - это основной способ выработки необходимых переводческих навыков, умений.

Проблемам разработки упражнений для обучения переводу посвящены многие работы зарубежных и отечественных исследователей. Однако в основном большинство из данных работ затрагивало упражнения для обучения письменному переводу. Устному переводу (УП) не было уделено должное внимание.

\author{
модель системь \\ упражнений, \\ обучение УПП, \\ навыки, \\ умение перевода
}

Данная публикация подготовлена на основе сообщения на международной онлайнконференции «70-летие вьетнамско-российских отношений в области науки и образования» (19 октября 2020 г.), г. Ханой, Вьетнам.
Для иитирования:

Ву Нгок Винь, Фам Куанг Лан. Универсальная модель разработки системы упражнений для обучения устному последовательному переводу вьетнамских студентов-филологов // Известия Восточного института. 2021. № 2 . C. 73-84. DOI https://doi. org/10.24866/2542-1611/20212/73-84 
В зарубежной литературе упражнения для обучения УП вообще и устному последовательному переводу (УПП) в частности рассматривались в работах Р. К. Миньяра-Белоручева [7], Т. С. Серовой [11], И. С. Алексеевой [1], А. П. Миньяра-Белоручевой и К. В. МиньяраБелоручева [6], Т. А. Казаковой [4], О. В. Железняковой [3] и др. Нужно отметить, что упражнения в названных учебных материалах, учебниках и пособиях посвящаются проблеме устного двустороннего перевода с русского на такие европейские языки, как английский, французский, немецкий, и в основном используются на переводческих факультетах языковых вузов России для подготовки профессиональных переводчиков, поэтому их применение к условиям обучения переводу во Вьетнаме, по нашему мнению, оказывается нецелесообразным и малоэффективным.

Во Вьетнаме мы не нашли более надёжной системы упражнений для обучения УПП с русского языка на вьетнамский. По нашему наблюдению, в созданных вьетнамскими авторами упражнениях по переводу отсутствуют системность и разнообразность типов и видов упражнений или не в должном объёме представляются упражнения, направленные на формирование и развитие необходимых навыков и умений для осуществления УПП [2].

Основываясь на теоретических и практических предпосылках составления упражнений для обучения устному переводу вообще, УПП в частности, мы разработали собственную систему упражнений, направленную на формирование и развитие навыков и умений УПП с русского языка на вьетнамский у студентов-филологов с переводческой ориентацией в рамках курса перевода на факультетах русского языка языковых вузов Вьетнама.

Из разнообразных видов и типов упражнений, разработанных в отечественной и зарубежной (в основном в русской) методической литературе, применительно к обучению одностороннему последовательному переводу, мы выбрали те, которые являются наиболее целесообразными и эффективными для формирования и развития навыков и умений у вьетнамских студентов в условиях отсутствия языковой среды. Система упражнений базируется на принципах постепенного нарастания трудностей, членения упражнений на блоки, учёта родного языка учащихся и их специальности, широкого комбинирования упражнений, направленных на достижение смежных целей, и целенаправленности упражнения. Следование намеченным принципам обеспечивает рациональность и эффективность создаваемой системы упражнений.

В соответствии с критерием функционально-стилистической и жанровой соотнесенности отбор текстов должен осуществляться в рамках определенных функциональных стилей, присущих конкретным сферам общения в реальной учебно-профессиональной коммуникации. Исходя из данного критерия отбора, включенные в систему упражнений тексты должны отражать такие жанры публицистического стиля, которые студентам часто приходятся встречать в переводческой деятельности, как выступления, интервью, беседы и т. д. И. С. Алексеева подчеркивает, что охват материала должен быть не только актуальным, лингвокультурологически насыщенным, но и максимально широким, с использованием разнообразных жанров текстов устного перевода (выступления, дискуссии, переговоры, ин- 
тервью, публичная речь, доклады и т. д.) и стилей (публицистический, разговорный), т. к. работа устного переводчика не ограничивается каким-либо одним жанром. Кроме того, тематика учебных текстов должна отражать требования и интересы современного рынка в сфере переводческих услуг [1, с. 352].

Специфику УПП, как любого другого вида устного перевода, определяют задействованные виды и формы переводческой деятельности. Это аудирование, запоминание, скоропись, трансформация и говорение, с каждым названным видом деятельности связаны соответствующие психологические механизмы и виды упражнений для выработки навыков, умений и операций УПП. В соответствии с действиями, которые приходится выполнить переводчику, с целью формирования и развития необходимых навыков и умений, предлагаем вниманию систему упражнений, в состав которой входят следующие блоки упражнений:

1) подготовительные упражнения, развивающие умение решать переводческие задачи, связанные с особенностями семантики языковых единиц и структур ИЯ и ПЯ;

2) операционно-переводческие, формирующие умение использовать различные способы и приёмы перевода, идущие от переводческого аудированияна ИЯ к устному оформлению перевода на ПЯ;

3) собственно-переводческие, вырабатывающие умение успешно выполнять необходимые действия на разных этапах переводческого процесса.

Ниже подробно представлена разработанная система упражнений для обучения УПП с русского языка на вьетнамский студентов-филологов с переводческой ориентацией. Модель системы упражнений представляется рисунком 1.

Ниже мы рассмотрим каждый блок упражнений и его типы:

\section{Блок 1. Подготовительные упражнения}

Умение и навыки перевода формируются на основе использования специально подобранных учебных материалов, которые можно разделить на подготовительные языковые (формирующие конкретные микронавыки) и переводческие упражнения (основные).

Каждое подготовительное упражнение независимо от его характера имеет трёх- или четырёхфазную структуру: 1) задача; 2) образец выполнения; 3) выполнение задания; 4) контроль выполненного задания. Образец исполнения является факультативным компонентом, так как в некоторых упражнениях он является необходимым, а в других нет никакой нужды.

В системе упражнений по обучению УПП к подготовительным упражнениям относятся: упражнения для работы над числительными, упражнения для работы над реалиями, упражнения для работы над географическими названиями, аббревиатурой, терминами и упражнения для работы над прецизионными словами. Рассмотрим некоторые типы из перечисленных подготовительных упражнений.

1.1. Упражнения для работы над числительными

Среди частей речи русского языка самыми трудными для усвоения вьетнамскими студентами материала являются числительные, сами по себе относящиеся к разряду прецизионных (однозначных) слов. Здесь имеются в виду простые, составные, сложные числительные, 


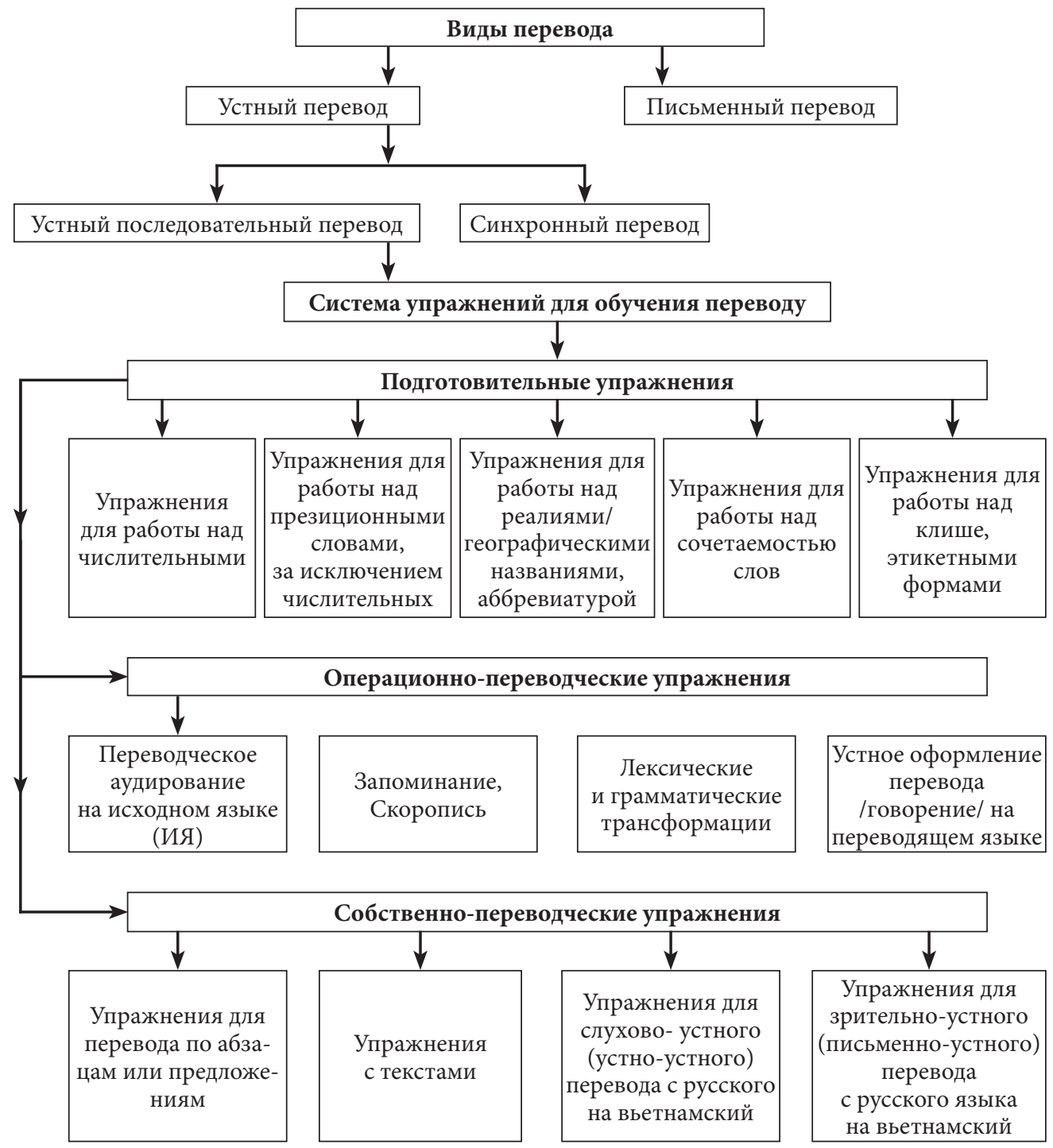

Рис. 1. Универсальная модель системы упражнений для обучения УПП. Источник: составлено авторами

${ }^{1}$ В этой схеме числительные со своими особенностями, отделённые от прецизионных слов, подчиняются методической цели. дроби, словосочетания с числительными (предложные и беспредложные) и т. п. Выделение числительных в курсе устного перевода в отдельную группу упражнений подчиняется методическим целям. Работа над числительными должна проводиться систематически, регулярно в начале занятия. Перевод-диктовка числительных - одно из упражнений, подготавливающих перевод на слух основных текстов, помогает совершенствовать и навык оперирования цифровым материалом, весьма часто вызывающим интерференцию родного языка учащихся.

Приведем несколько примеров упражнений с числительными:

- Замените прописи цифрами, обращая внимание на их способы чтения. 
- Прослушайте, запишите следующие номера телефонов.

- Прослушайте следующие ряды чисел, дроби.

- Прослушайте и переведите следующие цифровые обозначения.

- Прослушайте и переведите следующие числительные, обращая внимание на ассоциативные (связанные) с ними социально-исторические события.

\section{2. Упражнения для работы над реалиями}

Реалии - это слова, обозначающие понятия, предметы и ситуации, не существующие в практическом опыте людей, говорящих на другом языке. Поскольку реалии не имеют эквивалентов в другом языке, то проблема перевода данного вида безэквивалентной лексики является одной из самых актуальных в лингвистике и переводоведении.

Отсюда необходимость практиковать данные слова при помощи подготовительных упражнений или факультативно, чтобы обогатить свой словарный запас по изучаемому языку и повысить эффективность переводческой компетентности. Для перевода реалий (как и для перевода терминов, заимствованных слов, аббревиатур, географических названий, наименований историко-культурных объектов, титулов и званий, названий учебных заведений и т. п.) с русского языка на вьетнамский обычно используются следующие способы: транскрипционный или транслитерционный (без родо-видового слова или с родо-видовым словом), семантический, калькирующий.

\section{Блок 2. Операционно-переводческие упражнения}

\section{1. Упражнения для аудирования}

УПП начинается с аудирования звучащей речи на исходном (русском) языке. Поэтому на начальном этапе обучения устному переводу студентов-филологов с переводческой ориентацией широко вводится аудирование, которое крайне необходимо будущему устному переводчику.

Студенты начинают устно переводить простые устные и письменные тексты с русского языка на родной.

Аудирование при устном переводе протекает в более сложных условиях, чем речевое умение аудировать, а именно: кратковременность восприятия, неповторяемость, короткотечность, ограниченность темпа речи оратора, большая нагрузка на память, требующих быстроты запоминания и предельной точности. Усложняет процесс аудирования и зависимость восприятия исходного сообщения от владения оратором техникой речи и условиями восприятия. Безусловно, можно считать, что аудирование при устном переводе играет первостепенно важную роль. Только при успешном понимании смысла исходного сообщения и его нюансов возможны надёжное запоминание и качественный перевод.

Восприятие и понимание при УПП связаны с такими механизмами аудирования, как механизмы оперативной памяти, языковой догадки, вероятностного прогнозирования и механизм осмысливания. Упражнения на формирование и развитие названных механизмов хорошо и многочисленно представлены при обучении аудированию как самостоятельному виду речевой деятельности. Однако при УПП эти механизмы происходят в условиях неповторяемости и кратковременности, поэтому в разработанной системе упражнений большое внимание было обращено на упражнения, обучающие названным ме- 
ханизмам в условиях УПП. Ниже представляется перечень названий примерных упражнений, направленных на формирование и развитие навыков и умений переводческого аудирования исходного сообщения:

- упражнения на выделение ключевых слов и определение предмета сообщения;

- упражнения на развитие умения разбивать текст на смысловые фрагменты;

- упражнения на выделение ключевой информации;

- упражнения на развитие механизма вероятностного прогнозирования.

В заданиях к этим упражнениям предлагаем последовательный односторонний перевод на слух с русского языка на вьетнамский отдельных фраз, небольших абзацев и мини-текстов, что способствует совершенствованию таких умений, как хорошее понимание устной речи, мысленный перевод и запоминание, а также развивает правильную речь на языке перевода. Задания к этой группе упражнений могли бы выглядеть следующим образом:

- Прослушайте название текста и его первую фразу и скажите, о чём может идти речь в тексте.

Прослушайте текст, определите абзац, содержащий главную информацию. Кратко изложите её на родном языке.

Прослушайте текст и разделите его на законченные смысловые отрезки.

Запишите основную мысль каждого смыслового отрезка. Затем кратко изложите содержание на родном языке.

2.2. Упражнения для обучения запоминанию

Запоминание большого объёма информации и порядка следования единиц информации обеспечивается развитой кратковременной памятью. Понимание и запоминание при УПП тесно связаны между собой. Однако требования к памяти определяются величиной и сложностью исходного сообщения. Величина запоминаемого текста обратно пропорциональна его сложности. Следовательно, в конечном счёте при последовательном переводе объективно измеряемым параметром может служить величина текста, которая может также зависеть и от темпа речи оратора, фонетики, плавности и связности его речи, логики изложения материала, акустических условий перевода.

Целью упражнений для обучения запоминанию являются развитие объёма кратковременной и оперативной памяти, освоение вспомогательных приёмов запоминания. Мнемотехника позволяет развить качественную и позиционную память, то есть запоминание большого объёма информации и порядка следования единиц информации. В качестве упражнений на тренировку и развитие мнемотехники рекомендуем выполнять следующие:

- упражнения «снежный ком» или упражнения с повторением, упражнения постепенного увеличения объёма припоминаемой информации;

- упражнения восприятия на слух ключевых элементов;

- точное воспроизведение фрагмента текста на родном языке;

- упражнение по развитию внимания переводчика.

2.2. Упражнения для обучения переводческой скорописи 
Очевидно, что возможности оперативной памяти переводчика не безграничны. Обычно при хорошо тренированной памяти запоминанию поддаётся высказывание, содержащее не более 2-3 пар причинно-следственных связей и состоящее из 1-2 предложений. Увеличение объёма исходного сообщения или его сложности приводит к тому, что память с ним уже не справляется, отсюда необходимость использования вспомогательных средств для её разгрузки. Именно таким средством и является переводческая скоропись. Однако скоропись помогает переводчику только в том случае, когда она доведена до автоматизма. В противном случае ведение переводческой скорописи может только усложнить процесс перевода.

Упражнения по обучению переводческой скорописи включают в себя следующие группы: а) первая группа упражнений направлена на обучение употреблению в переводческой скорописи общеизвестных и общепринятых аббревиатур, знаковых обозначений, символов; б) упражнения второй группы нацелены на обучение употреблению сокращённых слов на родном и иностранном языках, условных знаков переводческой скорописи; в) третья группа упражнений направлена на развитие умения фиксировать прецизионную информацию в быстром темпе.

Задания к этим упражнениям могут быть следующими:

- прослушайте на родном/иностранном языке, зафиксируйте и восстановите в естественном темпе на языке оригинала/перевода предложенную последовательность чисел.

- прослушайте на родном/иностранном языке, зафиксируйте и восстановите в естественном темпе на языке оригинала/перевода следующие даты.

- зафиксируйте и восстановите в естественном темпе предложенный список русских поэтов и писателей и годы их жизни.

- зафиксируйте и восстановите в естественном темпе предложенный список руководителей Российского государства.

2.3. Упражнения, направленные на устное оформление перевода

К устному оформлению перевода исходного русского текста на вьетнамский язык следует подходить особенно внимательно, потому что оно выступает в качестве критерия всей работы переводчика. Именно оформление перевода показывает, насколько глубокое и отчетливое понимание исходного текста было достигнуто в процессе восприятия речи. Оформление позволяет также судить, насколько развит навык и умение переключения с одного языка на другой.

Для формирования навыков и умений устного оформления перевода исходного текста на вьетнамский язык рекомендуем следующие упражнения:

- упражнения, обучающие выработке навыков применения переводческих трансформаций (приёмов);

- упражнение в автоматизированном употреблении в речи эквивалентов наиболее употребительной лексики общественно-политического характера и грамматических структур.

- упражнение в технике устной речи;

- упражнения для формирования навыка переключения с русского яззыка на вьетнамский.

Умение переводить устно предполагает знание наиболее частотных употребительных соответствий двух языков, которые, как образ- 
но выразился Я. И. Рецкер, «являются своего рода катализаторами в процессе перевода. Их роль трудно переоценить особенно в процессе устного перевода. Именно эти единицы перевода, имеющие постоянные соответствия в родном языке, прежде всего проясняются в сознании переводчика и помогают ему понять значение окружающего контекста и всего высказывания в целом, даже содержащего незнакомые слова» $[10$, с. 49]. Однако знание переводческих соответствий не является достаточным для устного переводчика. Мы полностью согласны с Л. К. Латышевым, который отмечает, что «устный переводчик должен с высокой степенью автоматизма использовать наиболее употребительные переводческие соответствия» [5, с. 280]. Именно поэтому упражнения на закрепление лексических, лексико-фразеологических и терминологических эквивалентов входят во все комплексы упражнений по обучению устному переводу: и последовательному, и синхронному в частности.

Здесь речь идёт о группе упражнений, в заданиях которых указывается задача подбирать эквиваленты, соответствующие лексической единице или грамматической структуре, подчёркивающие в предложениях или текстах на русском языке. При этом в задачу студента может входить, например:

- перевод изолированных языковых единиц, передача значений указанных единиц и структур в составе высказываний,

- перевод высказываний, содержащих определенные единицы и структуры.

\section{Блок 3. Собственно-переводческие упражнения}

В системе упражнений для обучения УПП, кроме подготовительных и операционно-переводческих блоков упражнений, завершающим и обязательным блоком выступают собственно-переводческие упражнения, то есть «такие структурные единицы методической организации материала вторичного порядка, которые обеспечивают предметные действия с этим материалом и формирование на их основе умственных действий» [12]. Следует отметить, что третий блок упражнений обеспечивает реальную переводческую коммуникацию путём использования умений и навыков, сформулированных и развитых в ходе выполнений упражнений первых двух блоков.

К упражнениям данного блока выдвигаются определенные требования. Так, обобщая существующие точки зрения, можно сформулировать следующие требования к собственно-переводческим упражнениям для обучения УПП: упомянутые упражнения должны функционировать как единый комплекс в пределах структурной единицы обучения (темы), то есть промежуточные задачи, решаемые соответствующими операциями (например, поиск эквивалента, аналога), должны преимущественно входить в состав более общих задач (перевода на уровне микротекста, текста).

Собственно-переводческие упражнения призваны тренировать переводческие навыки и умения, то есть они направлены на тренировку точного перевода и на формирование навыков общего восприятия услышанной информации, её структурирование, резюмирование или на работу с отдельными частями текста для развития УПП на иностранном языке. Собственно-переводческие упражнений - это самый большой блок упражнений в системе обучения УПП, успеш- 
ное выполнение которых свидетельствует о том, что навык освоен и компетенция сформирована. Основным заданием таких упражнений является перевод учебных или реальных материалов и дальнейшая работа с ними. В блок заданий на собственно перевод включаются следующие виды: письменно-устный (или зрительно-устный) последовательный, устно-устный последовательный перевод диалога (беседы), в том числе и двусторонний. К ним относятся задания на: аудирование (запись выступления в виде монологического текста и двусторонний перевод в лингафонном кабинете); развитие навыков и умений передачи основной информации на языке перевода после прослушивания текста на языке оригинала; нахождение определённых данных на языке оригинала для включения их в текст перевода (путём сужения, расширения, добавления, опущения, замены... информации текста); устное аннотирование на русском языке текста, прочитанного на вьетнамском языке или обратно. Для третьего блока характерны следующие задания:

- сделайте абзацно-фразовый перевод следующих сообщений/текстов на вьетнамский язык;

- сделайте слухово-устный (устно-устный) перевод следующих сообщений/текстов на вьетнамский язык (без опоры на текст на русском языке);

- сделайте зрительно-устный (письменно-устный) перевод следующих сообщений/текстов на вьетнамский язык (с опорой на текст на русском языке);

- сделайте полный (или реферативный/сокращённый) устный последовательный перевод с записью следующих сообщений/текстов на вьетнамский язык, используя все возможные виды скорописи;

- прослушайте и переведите сначала в полной, затем в сокращённой форме следующий абзац (текст);

- прослушайте и переведите следующий текст на вьетнамский язык (чтение с соответствующими интервалами для устного перевода);

- работая в парах, передайте основное содержание текста на вьетнамском языке (первый студент) и переведите высказывание своего партнёра с вьетнамского языка на русский (второй студент).

Итак, разработанная модель системы упражнений в рамках этой статьи моделирует не всю деятельность переводчика в целом, а лишь её определённую часть. Виды и типы упражнений могут быть направлены на формирование как отдельных конкретных навыков и умений, так и группы навыков. Упражнения должны быть направлены на накопление и расширение словарного запаса обучаемых: лексических, грамматических, лексико-фразеологических и терминологических эквивалентов из общественно-политической сферы. Упражнения также отрабатывают отдельные переводческие приёмы, например, приёмы трансформации, смыслового анализа или компрессии и т. д. Всё это будет способствовать более успешному овладению УПП.

\section{Заключение}

Результат опытного обучения подтверждает наше предположение о том, что разработанная универсальная модель системы упражнений отвечает всем требованиям к системе. Во-первых, она является целостной, ее свойства не сводятся к сумме свойств ее составляющих, а каждый элемент зависит от его роли и места, а также его функции в 
системе. Во-вторых, она соответствует требованиям структурности, имея чёткую и ясную структуру, а также обеспечивает взаимозависимость системы и среды: формирует и проявляет свои свойства во взаимодействии с действующими (в каждый конкретный момент) требованиями до обучения переводу. В третьих, данная модель системы упражнений отвечает требованиям иерархичности. Её многочисленные уровни являются подсистемами по отношению к высшим уровням и системами - по отношению к низшим.

Разработанная универсальная модель системы упражнений для обучения УПП вьетнамских студентов-филологов соответствует требованиям множественности описания, позволяя построить различные её подсистемы (допустим, для обучения УПП в рамках вузовской подготовки студентов-филологов и переводчиков устного перевода), каждая из которых рассматривается как один из аспектов системы. Удовлетворение требования множественности обеспечивает динамичность и открытость определенной системы, которая (так же как и ее подсистемы) может варьироваться в зависимости от потребности общества, легко интегрируя в свой состав новые подсистемы, призванные удовлетворить конкретные запросы.

Созданная модель системы упражнений рассматривается как универсальная, поскольку на основе этой модели можно разработать специализированные системы упражнений, предназначенные для конкретного контингента учащихся в каждом языковом вузе Вьетнама. Тем более материал разработанной системы упражнений может быть использован также при составлении учебников и пособий по теории и практике обучения УПП не только во вьетнамской, но и в иностранной аудитории.

\section{Литература}

1. Алексеева И. С. Введение в переводоведение: учеб. пособие для студ. филол. и лингв. фак. высш. учеб. заведений. 6-е изд. стер. СПб.: Филологический факультет СПбГУ; М.: Академия, 2005. 368 с.

2. Ву Нгок Винь. Пособие по обучению устному переводу (для студентов-филологов Ханойского университета). Ханой, 2008. 124 c.

3. Железнякова О. В. Successful interpreting. Сборник заданий по устному переводу с аудио- и видеоприложением. Сетевое электронное учебное издание. Мн, 2012. 93 c. ORL: http://elearning. mslu.by/assignments/37/ (дата обращения: 01.09.2020).

4. Казакова Т. А. Практические основы перевода. English - Russian. СПб.: Союз, 2006. 320 c.

5. Латышев Л. К. Технология перевода. М.: НВИ-ТЕЗАУРУС, 2001. 280 с.

6. Миньяр-Белоручева А. П., Миньяр-
Белоручев К. В. Английский язык. Учебник устного перевода. 4-е изд. стер. М.: Экзамен, 2008. 350 c.

7. Миньяр-Белоручев Р. К. Пособие по устному переводу (Записи в последовательном переводе) для институтов и факультетов иностранных языков. М.: Высшая школа, 1969. $191 \mathrm{c}$.

8. Нгуен Ван Тоан. Система упражнений для обучения конспектированию аудитивных текстов научного стиля студентов в Военно-технической Академии. Автореф. дисс. канд. пед. наук. Ханой, 2011.24 c.

9. Нечаева В. М. Методика обучения переводческой деятельности (в рамках курса русского языка как иностранного). М.: Русский язык, 1994. 85 с.

10. Рецкер Я. И. Теория перевода и переводческая практика. Очерки пингвистической теории перевода. М.: Р. Валент, 2004. 204 c. 
11. Серова Т. С. Упражнения в устном последовательном одностороннем переводе // Теория и практика перевода и профессиональной подготовки переводчиков: материалы междунар. науч-практ. конф. (16-17 фев. 2005 г.). Пермь.: ПГТУ, 2005.
C. 103.

12. Черноватый Л. Н. Методика преподавания перевода как специальности: учебник для студентов высших учебных заведений по специальности «Перевод». Винница: Новая книга, 2013. 376 с.

\section{Ngoc Vinh VU,}

Ph. D. (in Pedagogy), Assosiate Professor, Hanoi National University (Hanoi, Vietnam)

E-mail: vinhiem2006@yahoo.com

\section{Quang Lan PHẠM,}

Postgraduate Student, University of Languages and International Studies, Vietnam National University (Hanoi, Vietnam)

E-mail: lanpquang@gmail.com

\section{Universal Model to Build a System of Consecutive Interpretation Exercises for Vietnamese Language-Specialized Students}

The article provides a description of a universal model to build a system of consecutive interpretation exercises for Vietnamese language-specialized students. The developed model includes three blocks of exercises, namely: preparatory exercises, manipulation exercises and translation exercises. In turn, each exercise block contains exercises to practice the corresponding
skills, techniques and consecutive interpreting operations. Built on the basis of generally recognized didactic and methodological principles along with particular ones taking into account the specificity of consecutive interpreting, the system of exercises simulates typical situations of translation activity appropriate for each stage. systematic model of exercises, teaching consecutive translation, skills, translation skills The publication is based on a presentation at an international online conference "70th anniversary of VietnameseRussian relations in the field of science and education" (October 19, 2020), Hanoi, Vietnam.

For citation: Ngoc Vinh Vu, Quang Lan Pham. Universal Model to Build a System of Consecutive Interpretation Exercises for Vietnamese Language-Specialized Students // Oriental Institute Journal. 2021. № 2. P. 73-84. DOI https://doi.org/10.24866/2542-1611/2021-2/73-84

\section{References}

1. Alekseeva I. S. Vvedenie $\mathrm{v}$ perevodu $\mathrm{s}$ audio- $\mathrm{i}$ videoprilozheniem. perevodovedenie: ucheb. posobie dlya stud. Setevoe ehlektronnoe uchebnoe izdanie. filol. i lingv. fak. vyssh. ucheb. zavedenij. 6-e Mn, 2012. 93 s. ORL: http://elearning.mslu. izd. ster. SPb.: Filologicheskij fakul'tet SPbGU; by/assignments/37/ (data obrashheniya: M.: Akademiya, 2005. 368 s. 01.09.2020).

2. Vu Ngok Vin'. Posobie po obucheniyu ustnomu perevodu (dlya studentov-filologov KHanojskogo universiteta). KHanoj, 2008. $124 \mathrm{~s}$.

4. Kazakova T. A. Prakticheskie osnovy perevoda. English - Russian. CPb.: Soyuz, 2006. $320 \mathrm{~s}$.

5. Latyshev L. K. Tekhnologiya perevoda.

3. ZHeleznyakova O. B. Successful M.: NVI-TEZAURUS, 2001. $280 \mathrm{~s}$. interpreting. Sbornik zadanij po ustnomu 6. Min'yar-Belorucheva A. P., Min'yar- 
Beloruchev K. V. Anglijskij yazyk. Uchebnik ustnogo perevoda. 4-e izd. ster. M.: EHkzamen, 2008. $350 \mathrm{~s}$.

7. Min'yar-Beloruchev R. K. Posobie po ustnomu perevodu (Zapisi v posledovatel'nom perevode) dlya institutov $i$ fakul'tetov inostrannykh yazykov. M.: Vysshaya shkola, 1969. $191 \mathrm{~s}$.

8. Nguen Van Toan. Sistema uprazhnenij dlya obucheniya konspektirovaniyu auditivnykh tekstov nauchnogo stilya studentov v Voenno-tekhnicheskoj Akademii. Avtoref. diss. kand. ped. nauk. KHanoj, 2011. $24 \mathrm{~s}$.

9. Nechaeva V. M. Metodika obucheniya perevodcheskoj deyatel'nosti ( $\mathrm{v}$ ramkakh kursa russkogo yazyka kak inostrannogo). M.:
Russkij yazyk, 1994. $85 \mathrm{s.}$

10. Retsker YA. I. Teoriya perevoda i perevodcheskaya praktika. Ocherki lingvisticheskoj teorii perevoda. M.: R. Valent, 2004. $204 \mathrm{~s}$.

11. Serova T. S. Uprazhneniya v ustnom posledovatel'nom odnostoronnem perevode // Teoriya i praktika perevoda i professional'noj podgotovki perevodchikov: materialy mezhdunar. nauch-prakt. konf. (16-17 fev. 2005 g.). Perm'.: PGTU, 2005. S. 103.

12. CHernovatyj L. N. Metodika prepodavaniya perevoda kak spetsial'nosti: uchebnik dlya studentov vysshikh uchebnykh zavedenij po spetsial'nosti «Perevod». Vinnitsa: Novaya kniga, 2013. 376 s. 